\title{
Pola Penambahan Larutan Tawas untuk Penurunan Kekeruhan Air Sungai Martapura
}

\author{
Noraida \\ Jurusan Kesehatan Lingkungan, Politeknik Kesehatan Kemenkes Banjarmasin, Indonesia \\ Email: noraida1972@gmail.com
}

\begin{abstract}
Modeling of Additional of Alum for Decreasing of Turbidity in Water of Martapura River. Most of the Martapura River water in Tambak Anyar Village is used by the community for daily needs such as bathing and washing. Physically Martapura River water in Tambak Anyar Village does not meet the requirements seen in terms of turbidity to be used as a source of clean water. Water sources that do not meet the requirements must be processed before they are used. It is known that the turbidity of Martapura River water does not meet the standards of clean water according to the Minister of Health Regulation No. 416/MENKES/PER/IX/1990, the level of turbidity of the clean water is a maximum of 25 NTU. Turbidity in water can be caused by suspended and dissolved organic and inorganic substances such as mud, fine sand, plankton, and other microorganisms. This research is an experimental study. The aim of the study was to create a model for adding alum solution to Martapura river water with turbidity and $\mathrm{pH}$ parameters. The results of the study showed that the level of turbidity of water along the river Tambak Hanyar Martapura village ranged between 101-904 NTU and the water pH ranged between 6.31-6.60. The dosage of alum solution to decrease the turbidity level of river water in Tambak Hanyar Village up to 25 NTU ranged from 0.100 to $2.946 \mathrm{ml}$. Distance regression model with alum dosage and $\mathrm{pH}$ at $25 \mathrm{NTU}$ turbidity is Alum Dose $=0.122+0.455$. (Distance). Doses in milliliters $(\mathrm{ml})$ and distance in kilometers $(\mathrm{km})$. It is suggested that the regression equation for decreasing the level of turbidity using the alum solution can be used according to the sampling point that has been done.
\end{abstract}

Keywords: Modeling, Alum, Turbidity, Martapura, River

\begin{abstract}
Abstrak: Pola Penambahan Larutan Tawas untuk Penurunan Kekeruhan Air Sungai Martapura. Sebagian besar air Sungai Martapura di Desa Tambak Anyar digunakan oleh masyarakatnya untuk keperluan sehari-hari seperti mandi dan mencuci. Secara fisik air Sungai Martapura di Desa Tambak Anyar tidak memenuhi persyaratan dilihat dari segi kekeruhan untuk digunakan sebagai sumber air bersih. Sumber air yang tidak memenuhi persyaratan harus dilakukan pengolahan terlebih dahulu sebelum digunakan. Diketahui kekeruhan air Sungai Martapura tidak memenuhi standar air bersih menurut Permenkes No. 416/MENKES/PER/IX/1990, tingkat kekeruhan air bersih maksimal 25 NTU. Kekeruhan pada air dapat disebabkan oleh adanya bahan organik dan anorganik yang tersuspensi dan terlarut misalnya lumpur, pasir halus, plankton dan mikroorganisme lain. Penelitian ini merupakan penelitian percobaan. Tujuan penelitian untuk membuat model penambahan larutan tawas pada air sungai Martapura dengan parameter kekeruhan dan $\mathrm{pH}$ air. Hasil penelitian diperoleh tingkat kekeruhan air di sepanjang sungai Desa Tambak Hanyar Martapura berkisar antara 101-904 NTU dan pH air nya berkisar antara 6,31-6,60. Dosis larutan tawas untuk penurunan tingkat kekeruhan air sungai Desa Tambak Hanyar hingga mencapai 25 NTU berkisar 0,100-2,946 ml. Model regresi jarak dengan dosis tawas dan pH pada pada tingkat kekeruhan 25 NTU adalah Dosis Tawas $=0,122+0,455$.(Jarak). Dosis dalam satuan mililiter $(\mathrm{ml})$ dan jarak dalam satuan kilometer $(\mathrm{km})$. Disarankan persamaan regresi untuk penurunan tingkat kekeruhan menggunakan larutan tawas dapat digunakan sesuai titik sampling yang telah dilakukan.
\end{abstract}

Kata kunci: Pola Penambahan, Larutan tawas, Kekeruhan, Sungai Martapura

Sebagian besar penduduk Indonesia belum dapat menikmati air bersih yang memenuhi syarat-syarat kualitas dan banyak masyarakat yang memanfaatkan air permukaan sebagai sumber air untuk keperluan sehari-hari. Pada tahun 2006 hanya 16 provinsi di Indonesia yang penduduknya telah memiliki akses pada sumber air yang terlindungi, arti terlindungi dalam hal ini adalah bersumber dari sebuah sumur atau air sungai yang telah disaring oleh perusahaan air 
untuk menghilangkan hampir semua sumber kontaminasi dan kemudian menyalurkannya melalui pipa. Pada tahun 2010 baru sekitar $47,71 \%$ penduduk yang telah memiliki akses pada air bersih (Sudaryono, 2013). Kehidupan masyarakat Kalimantan Selatan sangat dekat dengan sungai, Sungai Martapura banyak digunakan oleh masyarakat sebagai sumber air untuk keperluan sehari-hari. Penggunaan air sungai sebagai air konsumsi oleh masyarakat di Kabupaten Banjar sendiri adalah sebesar 26\% dan persentase rumah tangga yang menggunakan air tidak layak konsumsi adalah 45,72\% (BPS, 2010).

Masalah yang sering ditemukan pada masyarakat bahwa air sungai yang digunakan cenderung memiliki kekeruhan yang tinggi sehingga perlu dilakukan pengolahan sebelum dapat digunakan. Pemeriksaan kekeruhan yang pernah dilakukan pada air Sungai Martapura menunjukkan kekeruhan air Sungai Martapura berkisar 13,5-50,9 Nephelometrik Turbidity Unit/ NTU (Hamzani, 2013).

Kekeruhan disebabkan oleh partikelpartikel dan bahan-bahan terlarut di dalam air termasuk diantaranya partikulat organik dan anorganik, dan bahan tersuspensi, dan bahanbahan terlarut yang berkontribusi terhadap warna air (Henley et al, 2000 dan Effendi, 2012). Kekeruhan dapat didefinisikan sebagai sifat-sifat air yang menyebabkan cahaya menjadi tersebar (Billota, 2008).

Menurut Lloyd (1985), peningkatan nilai turbiditas (kekeruhan) sebesar 5 NTU di danau dan sungai dapat mengganggu proses fotosintesis fitoplankton dan tumbuhan air, dimana di dalam air akan dihasilkan senyawa organik dan oksigen yang sangat dibutuhkan oleh organisme akuatik (produktivitas primer) sebanyak $75 \%$. Apabila tingkat kekeruhan tinggi akan melindungi mikroorganisme dari pengaruh desinfeksi, mendorong pertumbuhan bakteri, dan menaikkan kebutuhan klor. Agar pada semua proses desinfeksi memperoleh hasil yang efektif, maka kekeruhan air harus selalu rendah (Chayatin, 2009).

Masalah yang sering ditemukan pada masyarakat bahwa air sungai yang mereka gunakan memiliki kualitas kekeruhan yang bervariasi. Menurut penelitian Hamzani (2013), diketahui kekeruhan air Sungai Martapura di Desa Tambak Anyar berkisar 13,5-50,9 NTU. Hasil pemeriksaan laboratorium tanggal 17 Maret 2016 terhadap sampel air Sungai Martapura di Desa Tambak Anyar diketahui kekeruhannya sebesar 51,8 NTU.
Kekeruhan pada air dapat disebabkan oleh adanya bahan organik dan anorganik yang tersuspensi dan terlarut misalnya lumpur, pasir halus, plankton dan mikroorganisme lain (APHA, 1976; Davis dan Cornwell, 1991 dalam Effendi, 2012).

Kekeruhan ini akan menghalangi penetrasi sinar matahari ke dalam air. Pada dasarnya, kekeruhan tidak mempunyai efek langsung terhadap kesehatan tetapi air yang keruh harus di olah terlebih dahulu agar dapat digunakan sesuai dengan fungsi air pada umumnya.

Dalam proses pengolahan air minum, optimasi pengolahan adalah sebuah hal yang menarik. Umumnya proses tersebut terdiri dari banyak unit seperti koagulasi, flokulasi, sedimentasi, filtrasi, dan desinfeksi (Farhaoui, 2016). Proses pengolahan air bersih tidak terlepas dari proses koagulasi. Selama ini dalam unit pengolahan air pada penurunan tingkat kekeruhan digunakan koagulan sintetik yaitu alum/tawas dan PACl (Poly Aluminium Chloride).

Tawas merupakan salah satu bahan yang dapat digunakan sebagai koagulan. Tawas mudah didapat dan murah harganya. Secara teori, tawas mampu mengendapkan zat-zat organik lebih cepat dibanding dengan koagulan Poly Aluminium Clorida (PAC) dan Ferric Chloride $\left(\mathrm{FeCl}_{3} \cdot 6 \mathrm{H}_{2} \mathrm{O}\right)$ (Sianita, 2009). Aluminum sulfate (A12 (SO4)3.18H2O) dan Ferric Chloride (FeCl3. 6H2O) digunakan dalam penelitian saat ini, sebagai jenis koagulan yang paling umum digunakan di banyak instalasi pengolahan air.

Tawas mempunyai rumus kimia $\mathrm{Al}_{2}\left(\mathrm{SO}_{4}\right)_{3}$ merupakan jenis yang umum digunakan sebagai koagulan pada berbagai tempat pengolahan air (Baghvand et al., 210). Senyawa tersebut di dalam air akan terurai menjadi ion-ion, yakni $\mathrm{Al}^{3+}$ dan $\mathrm{SO}_{4}{ }^{2-}$. Ion-ion tersebut akan berikatan dengan ion-ion yang ada dalam air dan terbentuk senyawa baru yang mempunyai sifat mudah mengendap, yaitu $\mathrm{Al}(\mathrm{OH})_{3}$. Sedangkan kapur merupakan bahan yang mempunyai rumus kimia $\mathrm{Ca}\left(\mathrm{CO}_{3}\right)_{2}$ yang merupakan perpaduan dari basa kuat $\left(\mathrm{Ca}^{2+}\right)$ dan asam lemah $\left(\mathrm{CO}_{3}^{-}\right)$sehingga dalam jumlah yang cukup akan dapat menaikkan $\mathrm{pH}$ air.

Garam-garam aluminum merupakan koagulan yang digunakan secara luas pada pengolahan air minum. Dengan menggunakan koagulan berbasis aluminum, air dengan perbedaan karakteristik kimiawi dan biologi yang besar berhasil diolah dengan baik. Proses koagulasi yang terjadi merupakan interaksi antara partikel koloid (kontaminan) dengan produk hidrolisa aluminum yang terbentuk dengan cepat saat proses pengadukan cepat (Winarni, 2003). 


\section{METODE}

Penelitian ini menggunakan jenis penelitian Experiment yaitu percobaan berupa perlakuan/intervensi yang dilakukan dengan sungguhan. Populasi dalam penelitian ini adalah air sungai Martapura. Sampel dalam penelitian ini adalah air sungai Martapura dari hulu sampai ke hilir di Desa Tambak Hanyar sebanyak 10 titik dengan interval 400 meter. Data nilai kekeruhan dan $\mathrm{pH}$ yang diperoleh dari hasil percobaan penambahan larutan tawas $2 \%$, kemudian ditabulasi dan dianalisis untuk menentukan ada tidaknya perbaikan kualitas air (kekeruhan dan $\mathrm{pH}$ ) setelah penambahan larutan tawas $2 \%$ dalam dosis berbeda-beda. Hasil percobaan juga dibandingkan dengan nilai parameter kekeruhan dan $\mathrm{pH}$ air yang terdapat dalam Keputusan Menteri Kesehatan Nomor 907/Menkes/SK/VII/2002. Kemudian dilakukan analisis korelasi untuk mengetahui ada hubungan antara penambahan larutan tawas dengan penurunan kekeruhan air sungai Martapura, jika berhubungan dilanjutkan dengan regresi untuk melihat model penambahan larutan tawas terhadap penurunan kekeruhan air sungai Martapura.

\section{HASIL}

\section{Tingkat Kekeruhan dan pH Air Sungai}

Sampel air sungai Martapura yang diambil dari hulu hingga ke hilir desa Tambak Hanyar dengan interval 400 meter sebanyak 10 titi sampel. Tingkat Kekeruhan dan $\mathrm{pH}$ air sungai Martapura di Desa Tambak Hanyar kecamatan Martapura kabupaten Banjar dapat dilihat pada Tabel 1.

Tabel 1. Tingkat Kekeruhan dan pH Air Sungai Martapura di Desa Tambak Hanyar

\begin{tabular}{crc}
\hline $\begin{array}{c}\text { Titik } \\
\text { Sampel }\end{array}$ & $\begin{array}{c}\text { Nilai } \\
\text { Kekeruhan } \\
\text { (NTU) }\end{array}$ & $\begin{array}{c}\text { Nilai } \\
\text { pH }\end{array}$ \\
\hline 1 & 340,4 & 6,55 \\
\hline 2 & 325,0 & 6,45 \\
\hline 3 & 904,0 & 6,33 \\
\hline 4 & 179,0 & 6,51 \\
\hline 5 & 108,0 & 6,50 \\
\hline 6 & 402,0 & 6,31 \\
\hline 7 & 257,0 & 6,60 \\
\hline 8 & 296,0 & 6,60 \\
\hline 9 & 211,0 & 6,50 \\
\hline 10 & 101,00 & 6,60 \\
\hline
\end{tabular}

Berdasarkan Tabel 1 nilai kekeruhan air sungai Martapura di Desa Tambak Hanyar kecamatan Martapura kabupaten Banjar berkisar antara 101-904 NTU dengan rata-rata 312,34 NTU. Sedangkan $\mathrm{pH}$ air sungai Martapura di desa Tambak Hanyar kecamatan Martapura kabupaten Banjar berkisar antara 6,31-6,60 dengan rata-rata 6,5 .

\section{Estimasi Kurva Nilai Kekeruhan}

Berdasarkan output estimasi kurva dapat diketahui nilai $\mathrm{R}$ Kuadrat Tingkat kekeruhan hasil pengolahan air sampel dari sungai Desa Tambak Hanyar seperti Tabel 2.

Data tingkat kekeruhan air sampel dari Desa Tambak Hanyar hasil perlakuan penambahan larutan tawas diestimasi menggunakan kurva linear, kuadratik, dan kubik.

Tabel 2. Nilai $R$ Kuadrat Kekeruhan Air Sungai Desa Tambak Hanyar

\begin{tabular}{crrr}
\hline \multirow{2}{*}{$\begin{array}{c}\text { Titik } \\
\text { Sampel }\end{array}$} & \multicolumn{2}{c}{ Nilai R Kudrat Kekeruhan Air } \\
\cline { 2 - 4 } & $\begin{array}{c}\text { Kurva } \\
\text { Linear }\end{array}$ & $\begin{array}{c}\text { Kurva } \\
\text { Kuadratik }\end{array}$ & $\begin{array}{c}\text { Kurva } \\
\text { Kubik }\end{array}$ \\
\hline 1 & 0,322 & 0,839 & 0,852 \\
\hline 2 & 0,560 & 0,887 & 0,909 \\
\hline 3 & 0,492 & 0,838 & 0,966 \\
\hline 4 & 0,446 & 0,790 & 0,951 \\
\hline 5 & 0,453 & 0,808 & 0,969 \\
\hline 6 & 0,387 & 0,725 & 0,902 \\
\hline 7 & 0,427 & 0,779 & 0,830 \\
\hline 8 & 0,384 & 0,725 & 0,907 \\
\hline 9 & 0,404 & 0,722 & 0,890 \\
\hline 10 & 0,485 & 0,792 & 0,924 \\
\hline
\end{tabular}

\section{Estimasi Kurva Nilai pH}

Berdasarkan output estimasi kurva dapat diketahui nilai $\mathrm{R}$ Kuadrat $\mathrm{pH}$ air hasil pengolahan air sampel dari sungai Desa Tambak Hanyar seperti Tabel 3. Data nilai $\mathrm{pH}$ air sampel dari Desa Tambak Hanyar hasil perlakuan penambahan larutan tawas diestimasi menggunakan kurva linear, kuadratik, dan kubik. 
Tabel 3. Nilai R Kuadrat pH Air Sungai Desa Tambak Hanyar

\begin{tabular}{crrr}
\hline \multirow{2}{*}{$\begin{array}{c}\text { Titik } \\
\text { Sampel }\end{array}$} & \multicolumn{2}{c}{ Nilai R Kudrat pH Air } \\
\cline { 2 - 4 } & $\begin{array}{c}\text { Kurva } \\
\text { Linear }\end{array}$ & $\begin{array}{c}\text { Kurva } \\
\text { Kuadratik }\end{array}$ & $\begin{array}{c}\text { Kurva } \\
\text { Kubik }\end{array}$ \\
\hline 1 & 0,968 & 0,979 & 0,980 \\
\hline 2 & 0,992 & 0,993 & 0,993 \\
\hline 3 & 0,990 & 0,994 & 0,997 \\
\hline 4 & 0,898 & 0,935 & 0,943 \\
\hline 5 & 0,940 & 0,941 & 0,950 \\
\hline 6 & 0,981 & 0,985 & 0,985 \\
\hline 7 & 0,988 & 0,989 & 0,989 \\
\hline 8 & 0,962 & 0,964 & 0,981 \\
\hline 9 & 0,985 & 0,988 & 0,988 \\
\hline 10 & 0,977 & 0,982 & 0,982 \\
\hline
\end{tabular}

\section{Dosis Tawas Optimal}

Pada tingkat kekeruhan 25 NTU maka dosis tawas dan nilai $\mathrm{pH}$ air sampel dari Desa Tambak Hanyar dapat diketahui seperti Tabel 4.

Berdasarkan Tabel 4 dosis larutan tawas yang diperlukan untuk memperoleh tingkat kekeruhan sebesar 25 NTU pada 10 (sepuluh) titik sampling berkisar antara $0,100 \mathrm{ml}$ sampai 2,946 ml. Sedangkan nilai $\mathrm{pH}$ berkisar antara 5,695 sampai 7,271.

Tabel 4. Dosis Tawas dan pH pada Kekeruhan Maksimal 25 NTU

\begin{tabular}{crc}
\hline $\begin{array}{c}\text { Titik } \\
\text { Sampel }\end{array}$ & $\begin{array}{c}\text { Dosis } \\
\text { Tawas (ml) }\end{array}$ & pH \\
\hline 1 & 0,100 & 7,271 \\
\hline 2 & 0,654 & 7,022 \\
\hline 3 & 1,455 & 6,481 \\
\hline 4 & 0,632 & 6,835 \\
\hline 5 & 0,502 & 6,920 \\
\hline 6 & 1,118 & 6,617 \\
\hline 7 & 1,767 & 6,323 \\
\hline 8 & 1,064 & 6,400 \\
\hline 9 & 0,988 & 6,662 \\
\hline 10 & 2,946 & 5,695 \\
\hline
\end{tabular}

Model Penambahan Larutan Tawas untuk Penurunan Kekeruhan

Untuk mengetahui model penambahan larutan tawas untuk penurunan tingkat kekeruhan dapat dilihat secara visual berdasarkan Gambar 1 . Model tersebut dilakukan untuk pada tingkat kekeruhan 25 NTU.

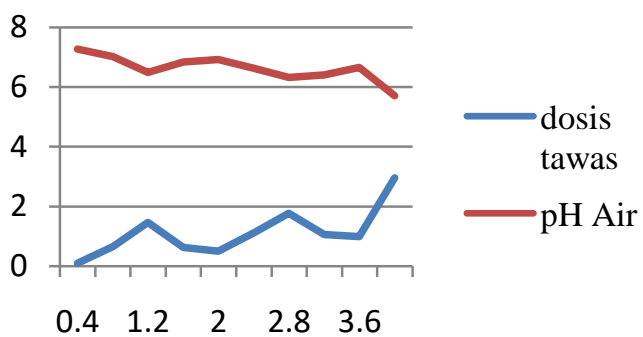

Gambar 1. Dosis Tawas dan pH pada Tingkat Kekeruhan 25 NTU

Gambar 1. juga menunjukkan pengaruh panjang sungai dalam bentuk jarak terhadap $\mathrm{pH}$ air sampel pada tingkat kekeruhan 25 NTU.

\section{Korelasi Jarak dengan Dosis Tawas dan pH}

Untuk mengetahui hubungan antara jarak dengan dosis tawas dan $\mathrm{pH}$ air sampel setelah penambahan larutan tawas pada tingkat kekeruhan 25 NTU maka dilakukan uji korelasi seperti Tabel 5.

Tabel 5. Korelasi Jarak dengan Dosis Tawas dan $\mathbf{p H}$

\begin{tabular}{lccc}
\hline \multicolumn{1}{c}{ Korelasi } & $\begin{array}{c}\text { Pearson } \\
\text { Corr }\end{array}$ & $\begin{array}{c}\text { Sig. } \\
\text { (2-tailed) }\end{array}$ & $\begin{array}{c}\text { R } \\
\text { Kuadrat }\end{array}$ \\
\hline Jarak dengan & 0,688 & 0,028 & 0,474 \\
Dosis Tawas & & & \\
\hline $\begin{array}{l}\text { Jarak dengan } \\
\text { pH }\end{array}$ & $-0,792$ & 0,006 & 0,627 \\
\hline
\end{tabular}

\section{Model Regresi Jarak dengan Dosis Tawas dan} pH

Model Regresi jarak dengan dosis tawas dan $\mathrm{pH}$ pada pada tingkat kekeruhan 25 NTU dapat dilihat pada Tabel 6 .

Tabel 6. Model Regresi Jarak dengan Dosis Tawas dan pH

\begin{tabular}{lc}
\hline \multicolumn{1}{c}{ Regresi } & \multicolumn{1}{c}{ Model Regresi } \\
\hline Jarak dengan & Dosis $=0,122+0,455$.(Jarak) \\
Dosis Tawas & \\
\hline Jarak dengan $\mathrm{pH}$ & $\mathrm{pH}=7,254-0,287 .($ Jarak)
\end{tabular}

\section{PEMBAHASAN}

Tingkat Kekeruhan dan pH Air Sungai Desa Tambak Hanyar

Sungai yang berada di Desa Tambak Hanyar merupakan bagian urat nadi kehidupan masyarakat sekitarnya. Masyarakat pinggiran sungai biasanya menggunakan air tersebut untuk keperluan sehari-hari seperti mencuci, mandi, dan 
lainnya. Sebagian masyarakat bahkan menggunakan sungai tersebut sebagai sarana untuk memancing dan bertambak ikan, bahkan ada yang menambang pasir di sungai tersebut. Selain kegiatan masyarakat, tentu kualitas air sungai Desa Tambak Hanyar juga sangat dipengaruhi oleh lingkungan sungai sendiri. Berdasarkan hasil pengukuran bahwa tingkat kekeruhan air di sepanjang sungai Desa Tambak Hanyar Martapura berkisar antara 101 NTU sampai 904 NTU dan $\mathrm{pH}$ air nya berkisar antara 6,31 sampai 6,60. Permenkes RI No.416 Tahun 1990 tentang Syarat-syarat dan Pengawasan Kualitas Air menyebutkan bahwa tingkat kekeruhan air bersih paling tinggi 25 NTU dan nilai $\mathrm{pH}$ dipersyaratkan berkisar antara 6,5 sampai 9,0. Jika tingkat kekeruhan air sungai Desa Tambak Hanyar dengan persyaratan tingkat kekeruhan menurut Permenkes RI tersebut maka dapat dikatakan bahwa tingkat kekeruhan air sungai Desa Tambak Hanyar tidak memenuhi persyaratan, sedangkan $\mathrm{pH}$ airnya masih dapat dikatakan memenuhi persyaratan.

\section{Estimasi Kurva Nilai Kekeruhan dan pH}

Berdasarkan Tabel 2 diketahui bahwa nilai $\mathrm{R}$ Kuadrat tingkat kekeruhan disemua titik sampling, yang terbaik adalah menggunakan model kurva kubik. Penggunaan model kurva linear akan berdampak bahwa nilai estimasi akan persamaan regresi akan sangat meleset jauh.

Meskipun demikian dalam rangka kesederhanaan persamaannya, maka model yang dipilih adalah model kuadratik karena nilai $\mathrm{R}$ Kuadrat yang dihasilkan pada tidak berbeda jauh dengan nilai R Kuadrat pada model kubik. Nilai $\mathrm{R}$ Kuadrat disebut juga dengan koefisien determinasi, Nilai ini menunjukkan tingkat kecocokan model (goodness of fit) dari model regresi. Nilai $R$ Kuadrat berkisar antara 0 sampai 1. Semakin tinggi nilai $\mathrm{R}$ Kuadrat maka model dikatakan semakin baik.

Nilai R Kuadrat tingkat kekeruhan dari 10 (sepuluh) titik sampling berkisar antara 0,733 sampai 0,887 . Kisaran ini sudah menunjukkan tingkat kecocokan model yang sangat baik karena mendekati nilai 1 .

Untuk model yang cocok untuk $\mathrm{pH}$ air menggunakan kurva linear karena selain nilai $\mathrm{R}$ Kuadratnya yang tidak berbeda jauh dengan model kurva kuadratik dan kurva kubik, model kurva linear ini juga sangat sederhana dalam pemodelannya. Nilai $\mathrm{R}$ Kuadrat $\mathrm{pH}$ air pada 10 (sepuluh) titik sampling di Desa Tambak Hanyar berkisar antara 0,898 sampai 0,992. Nilai $R$ Kuadrat $\mathrm{pH}$ air ini sudah sangat baik karena sudah sangat mendekati nilai 1, yang menunjukkan tingkat kecocokan model yang sangat baik.

Oleh karena sudah ditetapkan model kurva regresi baik model kurva tingkat kekeruhan maupun $\mathrm{pH}$ air maka persamaan regresinya dapat ditentukan. Persamaan regresi untuk tingkat kekeruhan pada 10 (sepuluh) titik sampling menggunakan model kurva kuadratik. Nilai konstanta berkisar antara 26,408 sampai 88,526; nilai beta 1 berkisar antara -55,997 sampai 9,361; sedangkn nilai beta 2 berkisar antara 1,443 sampai 8,456.

\section{Korelasi Jarak dengan Dosis Tawas dan pH}

Jika dilihat dari identifikasi model penambahan larutan tawas pada tingkat kekeruhan 25 NTU secara visual pada Gambar 1, maka nampak bahwa semakin jauh jarak aliran air sungai menuju hilir Desa Tambak Hanyar maka semakin banyak dosis tawas yang diperlukan untuk mencapai tingkat kekeruhan 25 NTU.

Hubungan antara jarak dengan dosis tawas dan $\mathrm{pH}$ air sampel setelah penambahan larutan tawas pada tingkat kekeruhan 25 NTU maka dilakukan uji korelasi seperti Tabel 5. Sedangkan model regresi jarak dengan dosis tawas dan $\mathrm{pH}$ pada pada tingkat kekeruhan 25 NTU dapat dilihat pada Tabel 6. Model persamaan regresi antara jarak dengan dosis larutan tawas yaitu:

Dosis Tawas $(\mathrm{ml})=0,122+0,455$. (Jarak dalam

Model sebaliknya ditunjukkan oleh model persamaan regresi antara jarak dengan $\mathrm{pH}$ air yang terjadi akibat penambahan larutan tawas, dimana semakin semakin jauh jarak aliran air sungai menuju hilir Desa Tambak Hanyar maka semakin menurun $\mathrm{pH}$ airnya sebagai dampak makin tingginya penambahan dosis larutan tawas untuk memperoleh tingkat kekeruhan yang sama yaitu 25 NTU. Model persamaan regresi jarak dengan $\mathrm{pH}$ air sebagai berikut:

$\mathrm{pH}=7,254-0,287 .($ Jarak dalam $\mathrm{km})$

\section{SIMPULAN}

Dosis larutan tawas untuk penurunan tingkat kekeruhan air sungai Desa Tambak Hanyar hingga mencapai 25 NTU berkisar antara $0,100 \mathrm{ml}$ sampai 2,946 ml. Model regresi jarak 
dengan dosis tawas dan $\mathrm{pH}$ pada pada tingkat kekeruhan 25 NTU adalah Dosis Tawas $=0,122+0,455$.(Jarak). Dosis dalam satuan mililiter (ml) dan jarak dalam satuan kilometer $(\mathrm{km})$.

\section{DAFTAR PUSTAKA}

Badan Pusat Statistik. 2010. Survei Sosial Ekonomi. Banjarmasin.

Baghvand A, Zand AD, Mehrdadi $\mathrm{N}$ and Karbassi A. 2010. Optimizing Coagulation Process for Low to High Turbidity Waters Using Aluminum and Iron Salts. American Journal of Environmental Sciences 6 (5): 442-448.

Billota GS and Brazier RE. 2008. Understanding The Influence of Suspended Solids on Water Quality and Aquatic Biota. Journal Science Direct 42: 2849-2861.

Chayatin, W.I. 2009. Ilmu Kesehatan Masyarakat; Teori dan Aplikasi. Jakarta: Salemba Medika

Effendi, H. 2012. Telaah Kualitas`Air bagi Pengelola Sumber Daya dan Lingkungan Perairan. Yogyakarta: Kanisius.

Farhaoui M and Derraz M. 2016. Review on Optimization of Drinking Water Treatment Process. Journal of Water Resources and Protection, 8: 777-786.

Hamzani, S. 2013. Proses Koagulasi dan Flokulasi Menggunakan Gravel Bed

\section{SARAN}

Secara praktis pemodelan jarak dengan dosis tawas dapat digunakan penduduk sepanjang sungai Desa Tambak Hanyar untuk menentukan dosis larutan tawas dalam penurunan tingkat kekeruhan. Secara teoritis diharapkan dapat digunakan untuk peningkatan pengetahuan tentang penurunan tingkat kekeruhan air.

Flocculator untuk Pengolahan Air Sungai Martapura di Kabupaten Banjar Kalimantan Selatan. Surabaya. [Tesis]. Surabaya: Institut Teknologi Sepuluh November.

Henley W.F, Patterson M.A, Naves RJ, and Lemly AD. 2000. Effects of Sedimentation and Turbidity on Lotic Food Webs: A Concise Review for Natural Resource Managers. Journal Reviews in Fisheries Science, 8(2):125-139

Sianita, Dwi; Nurchayati, I. S. 2009. Kajian Pengolahan Limbah Cair Industri Batik, Kombinasi Aerob-Anaerob Dan Penggunaan Koagulan. [Skripsi]. Bandung: Jurusan Teknik Kimia UNDIP.

Sudaryono. 2013. Pengelolaan Sumber Daya Air Guna Mendukung Pembangunan Nasional Dalam Rangka Ketahanan Nasional. Jurnal Kajian LEMHANAS RI, 15, 3.

Winarni. 2003. Koagulasi menggunakan Alum dan PACl. Jurnal MAKARA, Teknologi, Vol.7 (3). 